giant New Technology Telescope (NTT) in the 15-metre class and a 10-metre submillimetre-wave antenna. All these devices would contribute to the solution of the astronomical problems highlighted in the report - the large-scale structure of the Universe, the evolution of galaxies, violent events (such as supernovae and processes in active galaxies and quasars), the formation of stars and planets and solar and stellar activity.

In the committee's view, AXAF is a must at a cost of $\$ 500$ million. The VLB has beaten the 15-metre telescope into second place because it would require considerably less preliminary development and would have by far the best angular resolution of all techniques -0.3 milliarc seconds possibly allowing the resolution of the nuclei of active galaxies and quasars at radio wavelengths. But because of the tremendous potential light-gathering power of the 15-metre telescope, an order of magnitude larger than present telescopes, the committee puts that on as high a level of scientific desirability as any other project examined.

The committee also urges increased support for what it calls prerequisites instrument design (including a request for declassification of certain infrared detectors), theory, data analysis, computing facilities and laboratory astrophysics. To handle the data from AXAF, the committee recommends that a special institute be set up in support of the satellite, analogous with the Space Telescope Institute. As a consequence of its recommendations, the committee sees the need for an increase in personnel at all levels.

In his foreword to the report, Herbert Friedman, chairman of the Mathematical and Physical Sciences Assembly of NAS, stresses the need for an increase in the relative contribution of ground-based astronomy and, consequently, the NSF contribution. He also says that the technology of new developments in astronomy is dependent on but will also contribute to areas of science and to industrial and military applications.

In the present climate, it is hard to see the astronomers having many major desires fulfilled. Of the major recommendations of the influential Greenstein report, the 1972 predecessor of the Field report, only one - the VLA radiotelescope - was implemented in the less austere 1970 s, for example. The Field committee emphasizes, however, that the level of expenditure it requests is equivalent in real terms to that which followed the Greenstein report. Moreover, Dr Friedman points out that they are hoping "that the purposes of the present fiscal policies will be achieved in a reasonably short period and that a healthier base of federal scientific support will then be restored"'. But if the Greenstein report can be viewed as a precedent, $\mathrm{X}$-ray astronomers have struck lucky.

\section{High-energy physics}

\section{Tunnel vision}

A legal obstacle to the construction of LEP, a European particle accelerator which should put European physics in the 1990s well ahead of the United States, has been removed. But the shouting is not yet over.

LEP - a large electron positron collider - will straddle the French-Swiss border in the plain of Geneva, linking with existing machines at the European Centre for Nuclear Physics, CERN. CERN has won cash and approval for the project from its member states, which include France and Switzerland, but the problem lately has been how to carry the project through local planning procedures in France and Switzerland. French environmentalists had managed by a legal technicality to block construction of an important exploration tunnel, but now the French court of appeal, the Conseild'Etat, has finally ruled that the tunnel can go ahead after all.

This, however, is only a minor victory. The main justification for the tunnel was that it would provide an escape route for both engineers and water if the main LEP ring - which originally led right under the $1,000 \mathrm{~m}$ high peak of the Jura mountains encountered high pressure water in the Jura limestone. But now the LEP ring has been shuffled almost entirely out of the Jura, by tipping it on its side (see figure), so water pressures will be lower. It will also now be possible to intervene from the surface if people are trapped.

However, there are still geological and political problems to solve. Geologically, the $3 \mathrm{~km}$ of LEP that will still lie in the Jura limestone lie entirely in the piémont, near the boundary with the sandstone of the plain. This rock is likely to be traversed by caverns and faults, and although vertical borings along the new route have revealed nothing serious, uncertainty persists.

Politically, the obstacle may still be the Association gessienne de protection de la Nature, the local French environmental organization presided over by M. JeanRoger Honorat, the mayor of Echenevex. This group blocked the construction of the exploration tunnel, and although CERN has wooed it ever since, it remains suspicious.

The group will play an active part in the French planning process now under way.

\section{New cancer research award}

The 1982 Bristol-Myers Award for Distinguished Achievement in Cancer Research has been awarded to Dr Denis Burkitt (of Burkitt's lymphoma) and Dr Michael Epstein (of the Epstein-Barr virus). Their $\$ 50,000$ award was presented to them in New York this week.

Dr Burkitt was Government Surgeon in Uganda some twenty years ago when he proposed, from epidemiological studies, that an infectious agent caused childhood lymphoma in Africa. Dr Epstein heard Burkitt speak in London

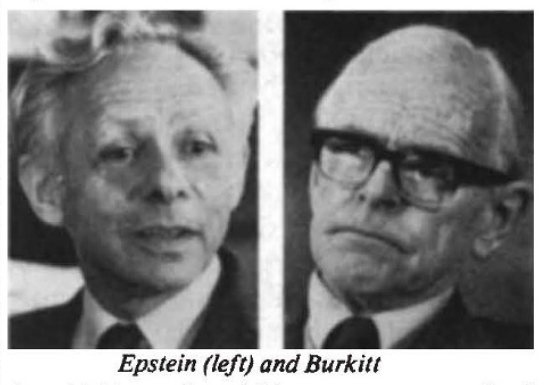

in 1961 and within two years had isolated the infectious virus that causes the lymphoma.

Burkitt is now an honorary senior research fellow at St Thomas's Hospital. in London. Epstein is professor of pathology at the University of Bristol. And Yvonne Barr, in case you were wondering, is an Australian housewife.

Peter Newmark

The French ministry of foreign affairs, with which CERN must deal, now has CERN's final environmental impact statement, and under French planning law will act on CERN's behalf. There is to be a local public inquiry at which anyone in the region may present his views. CERN itself will be represented at the inquiry only if needed to explain technicalities; it has no right to plead. Eventually the results of the inquiry and files of submissions will be returned to Paris for a decision by the Conseil d'Etat.

Meanwhile, CERN is about to invite tenders for the construction of the tunnel, which should be in by the autumn. A decision from the Conseil d'Etat is not expected before the end of this year but a delay beyond that would mean LEP would not be producing particle collisions by the end of 1987 as planned. Robert Walgate

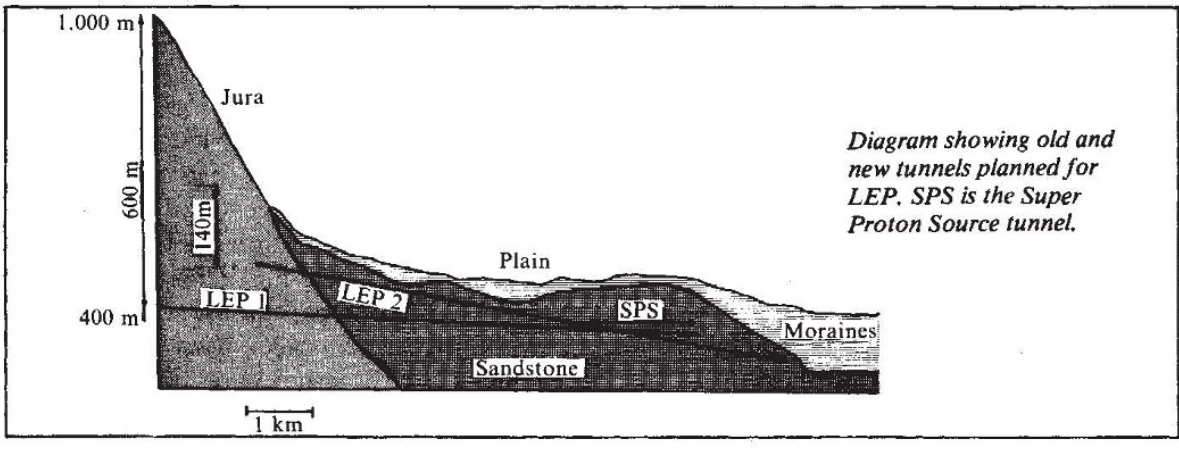

